\title{
Joaquim Benite Interrogações postas ao mundo, à vida e à arte
}

\section{Maria Helena Serôdio}

1.

Nascido em 1943, Joaquim Benite, filho de um empresário de teatro, cedo se deixou atrair pela escrita e, mais em particular, pelo jornalismo. Tendo-se iniciado no Diário de Lisboa Juvenil (então dirigido por Mário Castrim), Joaquim Benite foi jornalista profissional no Diário da República, Diário de Lisboa, Primeiro de Janeiro, 0 Século e O Diário, tendo em alguns destes casos assumido uma posição destacada: de chefe de redacção (n'OSéculo) ou de direcção do Suplemento Cultural (n' O Diário). Isto nos anos Sessenta e primeira metade de Setenta.

Ouvi-lo contar histórias desses tempos, desses circuitos, desses modos de estar, é apreciar a escola cívica em que se integrou, o nervo e a energia que por ai circulavam e que ele acompanhou com avidez e desassombro. Criavamse cumplicidades, descobriam-se pequenas - e grandes traições, vivia-se um permanente espirito de alerta, não faltavam momentos de aflição, mas também de alegria transbordante. 0 gosto pela tertúlia, o espirito satírico, a pequena maledicência, a desconfiança relativamente aos académicos (ainda hoje, infelizmente, mas injusta quantas vezes...), o prazer da discussão acesa, noite fora, esgrimindo argumentos, desfiando projectos, acalentando devaneios. Essas foram algumas das teias da vida que Joaquim Benite viveu com superlativa afeição.

Suponho que levar à cena a peça de José Saramago A noite (em 1979) deve ter soado a Joaquim Benite como preciosa memória de um tempo histórico, mas também de parte da sua vida: invocar a revolução dos cravos e rever o que nessa noite se decidia da história, simbolizada na oposição e no conflito entre a redacção e os tipógrafos num grande jornal nacional.

No trajecto que Joaquim Benite realizou pelos periódicos, a que esteve ligado, podemos destacar - pela sua importância jornalística e pelo seu valor cultural dois pólos de actuação que nele estão, de facto, fundidos numa só forma de ver, compreender e dar valor ao mundo: o plano político, de um lado, a esfera artística e cultural, do outro. Inseparáveis, interligados, vertendo-se de um para o outro lado, a tempo inteiro.

Porque para ele sempre fez - e continua a fazer sentido a articulação pensada e vivida no cruzamento destes dois planos, porque essa é a moldura do humano em sociedade, e essa é (para ele, mas felizmente não só para ele) a melhor forma de medir a razão última do fazer artístico e, mais que tudo, do teatro.

A sua intervenção política incluiu a participação, como Membro da Comissão Política Nacional da CDE - Comissão Democrática Eleitoral - em 1969, e a responsabilidade por reportagens, entrevistas, crónicas e artigos de opinião que se centravam em questões candentes como a cobertura do II Congresso Republicano de Aveiro ${ }^{1}$, a situação da Espanha na fase final do Franquismo, a interpelação a destacadas figuras do mundo artístico, como Rafael Alberti, Maria Barroso, Aquilino Ribeiro ou Miguel Torga, entre outros.

Como crítico de teatro, Joaquim Benite sempre soube fazer convergir estas suas competências no processo de analisar, compreender e avaliar o que se mostrava em cena. Há, de facto, nas suas críticas, uma capacidade notável para analisar um espectáculo, interrogando a sua relação com o texto de que parte (o que é para ele o elemento-chave para aferir a correcção do projecto cénico), e valorizando o que em cena prova ser uma leitura inteligente e acertada da obra. Com efeito, sem recusar a importância da visualidade, é em função da sua pertinência na clarificação daquele universo dramático e poético que Benite ajuiza o seu valor teatral.

Denuncia, várias vezes, como artificial o trabalho vocal do actor (referindo a afectação e o declamatório), critica o desequilibrio entre a valorização plástica da cena (por vezes em espiral gratuita) e uma fraca relação com uma mais aprofundada leitura dramatúrgica da peça, invectiva o facilitismo de recorrer a estereótipos para a invocação de um portuguesismo que se revela, afinal, mistificador.
V. Diário de Lisboa, 18-05-1969. 
Joaquim Benite e Emmanuel Demarcy-

Mota, 2009

(no Festival de Almada), fot. Da Maia Nogueira.
Joaquim Benite

e Rodrigo Francisco, 2010 (ensaios da peça Tuning) fot. Rui Carlos Mateus.

Pilar del Río, José Saramago,

Joaquim Benite,

Presidente da Câmara de

Almada: Maria Emilia

Neto de Sousa, 2008,

fot. José Frade.

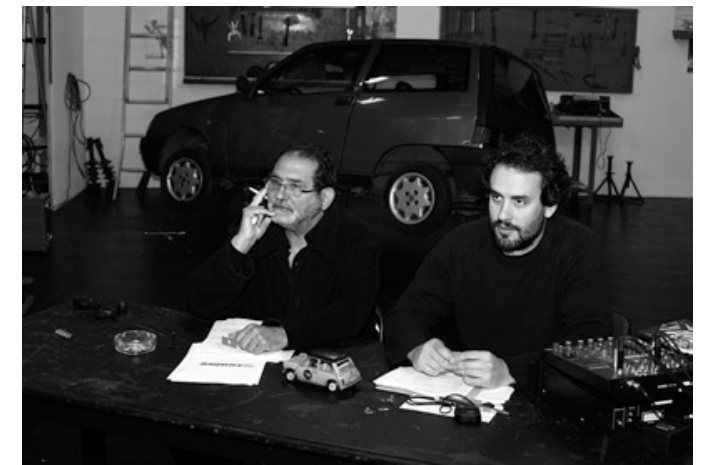

Mas sabe também sinalizar competências artísticas, reconhecer talento em jovens actrizes e actores, estar atento a outras dimensões do espectáculo, em particular à música, como faz relativamente a Carlos Paredes, por exemplo, no espectáculo Bodas de sangue que Carlos Avilez encenou para o Teatro Experimental de Cascais (Diário de Lisboa, 15-09-1968).

Impacienta-se com as soluções fáceis no uso de estereótipos na caracterização de um tempo e um lugar alimentando uma visão deturpada da vida, "rodriguinhos" vendidos como caracterizando a portugalidade, como escreve a propósito de um espectáculo que em 1966 subiu ao palco do Teatro Avenida:

Um principe do meu bairro alimenta-se dessa concepção fatalista da vida que tem sido a pecha principal do lamentável regionalismo que alimenta grande parte do nosso teatro chamado poético.

0 equivoco reside aqui: o poético é sinónimo, para muitos, de metafísica de filosofia barata, de declamação retórica e de desvirtuamento da realidade popular [...] pela captação da sua exterioridade, do aspecto exótico que ela assume aos olhos folcloristas e românticos de certos autores que se julgam muito modernos e... realistas. Sim, demagogia... Apenas demagogia... (Diário de Lisboa, 31-07-1966)

$\mathrm{Na}$ aproximação aos mundos ficcionais, Benite sempre soube perceber as duas dimensões legiveis: a realidade inventada (na sua coesão e verosimilhança) e a evocação do mundo real, com os seus conflitos sociais e as suas disfunções políticas.

Foi o que fez, por exemplo, com Cartas na mesa, espectáculo encenado por Fernando Gusmão em 1969, sobre peça de Buero Vallejo, e que servirá também para sublinhar - e enaltecer - a "lúcida encenação" que tão bem soube actualizar em cena essa dupla valência do texto na vertente histórica, social e psicológica. Contando com um elenco de grande qualidade, bem dirigido por
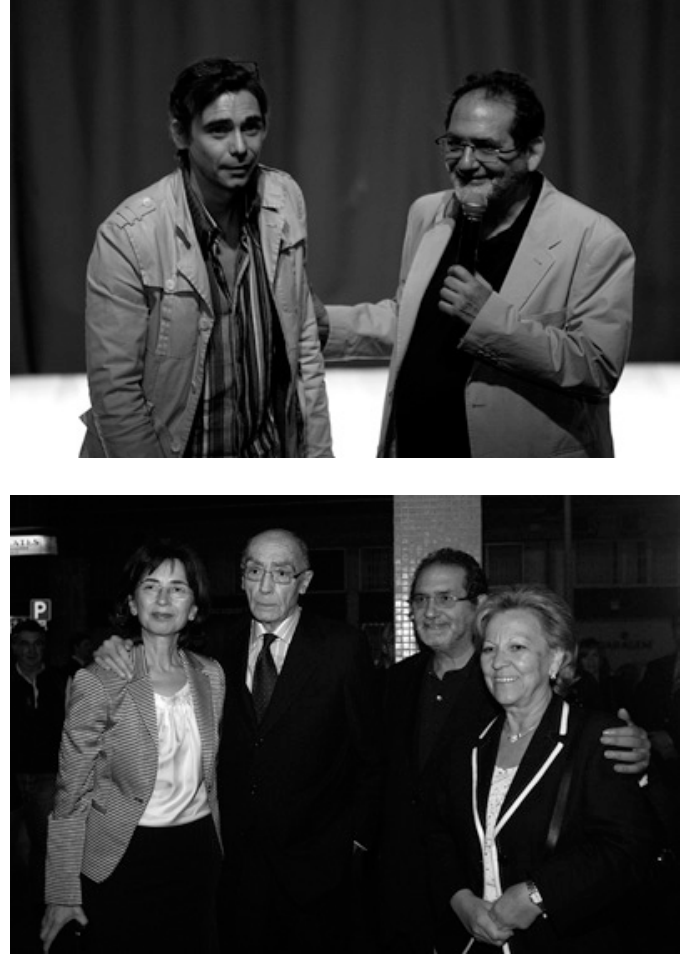

Fernando Gusmão, o espectáculo provava o acerto de uma forma nova de fazer teatro entre nós:

Fernando Gusmão tem na encenação desta peça de Buero Vallejo um trabalho que se insere na linha das suas realizações anteriores, pela qualidade estética, pela lucidez dos processos utilizados, pelo sentido raro entre nós, de uma linguagem teatral depurada e amadurecida. Recusando todos os excessos, procurando o rigoroso e o significante, Gusmão encontra um estilo sem o qual a representação de Cartas na mesa nunca poderia ter tido o sentido ideológico e o peso plástico que avultam no espectáculo. (Diário de Lisboa, 10-04-1969)

A exigência que coloca na avaliação crítica não confunde o respeito que the possam merecer as intenções de autores e companhias com o que sempre exigiu do teatro: uma interpelação viva da realidade social e política, que para ele não se confunde apenas com um presentismo redutor, antes advoga uma leitura histórica e política de todos os tempos e que, simbolicamente, se reelabora na escrita dramática.

E respeitando embora artistas com valor e comemorações justas, Joaquim Benite não se coíbe de perceber um valor menor em algumas dramaturgias nefelibatas que denegam a importância de saber ler o mundo político e social. Pressente-se isso na critica a um espectáculo na Casa da Comédia, encenado por Norberto Barroca - A caixa de Pandora-, que pretendia celebrar Fernando Amado, recentemente falecido. Nas palavras de Benite, Fernando Amado (o autor da peça e encenador do grupo que actuava na Casa da Comédia) "passe[ara] pela vida [como] um espírito curioso, marcado pela necessidade de uma constante vivência poética e por um quase lírico inconformismo, que um idealismo desligado do mundo fundamentalmente alimentava". (Diário de Lisboa, 21-02-1969, p. 6). 0 equívoco que detecta no universo dramático de Fernando Amado, e 


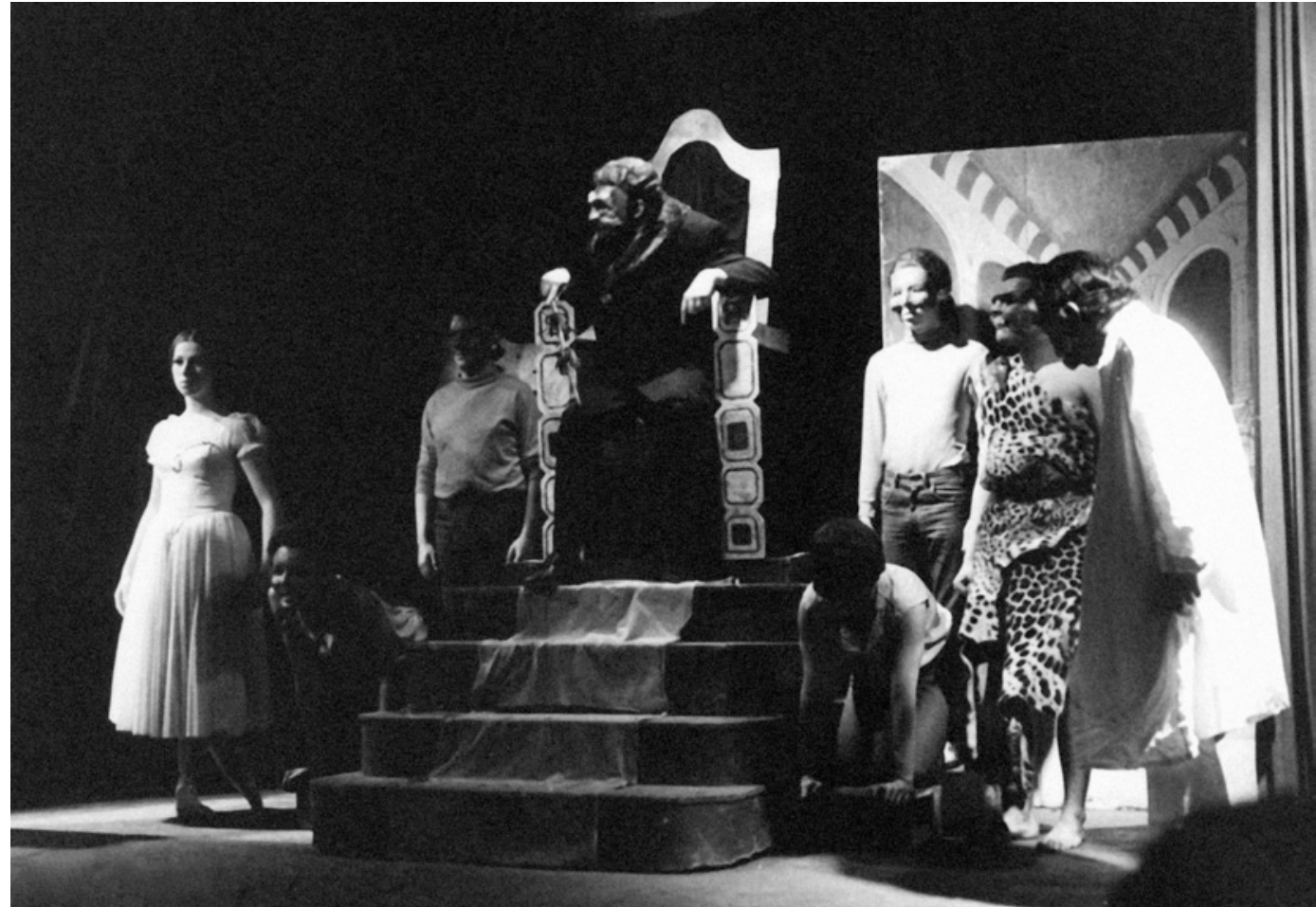

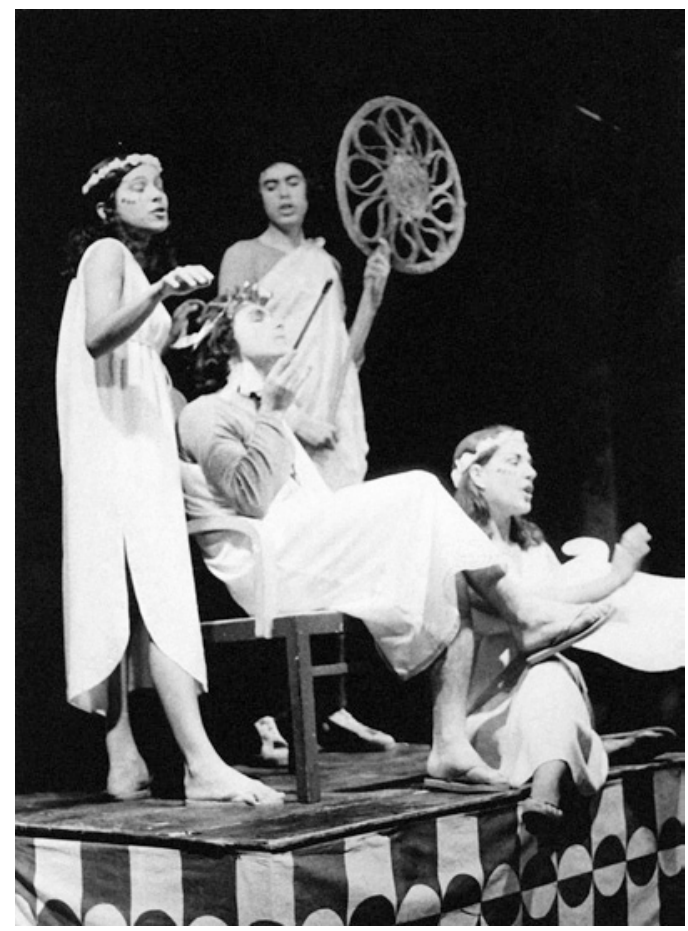

particularmente em Caixa de Pandora, é sucintamente apresentado na sua crítica ao espectáculo:

A alegoria parte, evidentemente, do equivoco fundamental de se pensar que todas as grandes personagens clássicas do teatro não nasceram como reflexo de condições sociais do tempo e do meio em que foram criadas. A proposta de abandono da relação do teatro com o actual não é, assim, uma defesa do teatro de sempre, mas tão-só um convite à paralisação do esforço de criar. Ou seja, e também, um convite à alienação - que em Fernando Amado não se chamaria assim, naturalmente, mas "convite ao sonho ou à evasão". (Diário de Lisboa, 21-02-1969, p. 6)
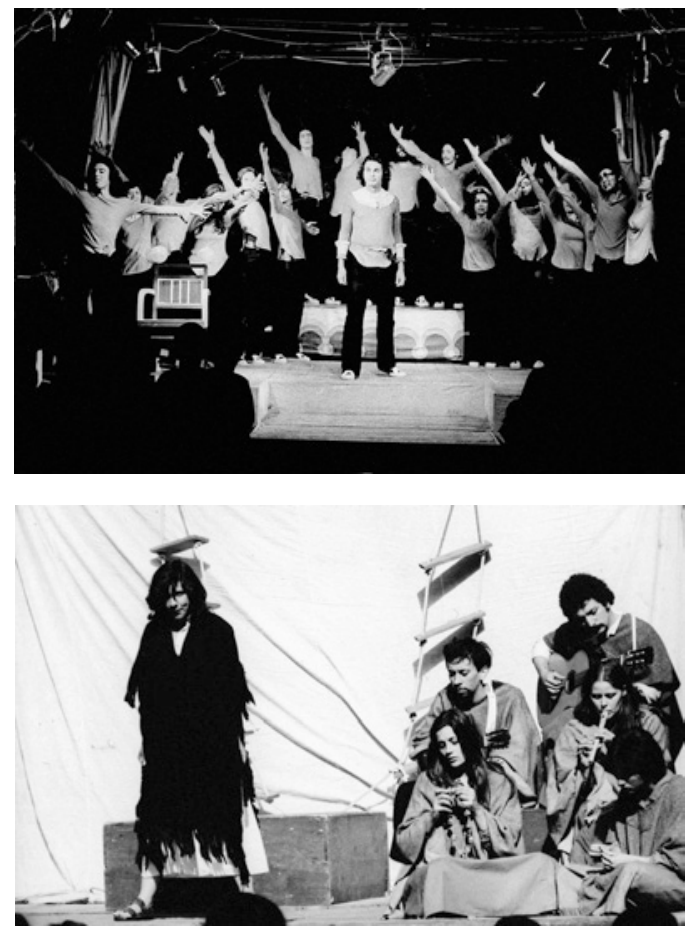

Percebe-se nas críticas de Joaquim Benite a sedução por um teatro de intervenção que, falando do presente ou representando o passado com sinais de uma estética mais contemporânea, saiba ler a condição histórica do fazer humano. E que ele detecta e analisa, por exemplo, em encenações de Adolfo Gutkin (Volpone, com os estudantes de Direito: Diário de Lisboa, 22-04-1969), ou na de Luis Miguel Cintra na sua já mítica estreia com Anfitrião pelo Grupo Cénico da Faculdade de Letras de Lisboa (Diário de Lisboa, 11-05-1969).

Se é certo que, enquanto crítico, Benite soube sempre abordar os espectáculos de uma forma analítica, servindo-
A vida do grande $D$. Quixote de La Mancha do gordo Sancho Pança de António José da Silva enc. Joaquim Benite, Grupo de Campolide, 1972 (< Sónia, Páscoa, José Saraiva: $>$ José Martins ao centro [Arquivo pessoal de Joaquim Benite].

Fulgor e morte de Joaquim Murieta, de Pablo Neruda, enc. Joaquim Benite, Grupo de Campolide, 1974 (Teresa Gafeira Pedro Artur, Fernanda Cardoso,

Ricardo Almeida, Raquel Carlos Alberto Machado [Arquivo pessoal de

Joaquim Benite 


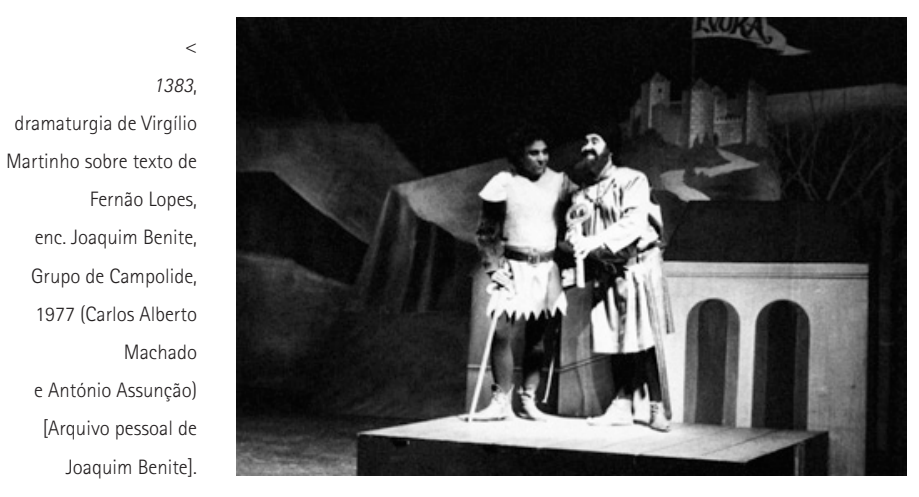

Mãe Coragem e os seus filhos

de Bertolt Brecht,

enc. Joaquim Benite,

Companhia de Teatro de

Almada, 2000

(Teresa Gafeira

e Maria Frade),

fot. Joaquim Nabais.

Memorial do convento

de José Saramago,

enc. Joaquim Benite,

Companhia de Teatro de Almada \&t Companhia de

Teatro de Sintra, 1999

(Jorge Sequerra

e Teresa Gafeira),

fot. José Frade.

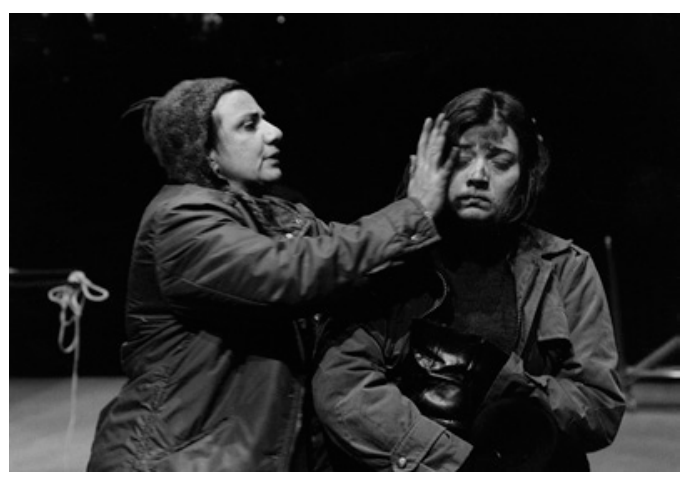

se do entendimento e avaliação do que em cena se mostrava a verdade é que, no tempo em que exercia esse labor, a situação política do país apresentava aberrações directamente decorrentes da falta de liberdade e da permanente intimidação. Por isso se entende a explosão indignada com que reagiu a um espectáculo da Companhia Rey Colaço - Robles Monteiro apresentado no Teatro Capitólio. Tratou-se de A esfera facetada, que para Benite foi "uma das mais dolorosas experiências", saudavelmente pateada pelo público que também vaiou o autor (Coronel Nuno Moniz Pereira). E a indignação não poderia subir mais de tom ao verificar a nulidade de um texto, escrito por um coronel do Estado Maior, que publicamente afirmava nada perceber de teatro, mas que a principal companhia de teatro da altura se vira "obrigada" a encenar:

Como é possivel que, estando por representar tantos textos de tantos autores portugueses modernos se consinta na realização de um espectáculo tão absolutamente confrangedor e irresponsável? [...] Nada do que se passou no Capitólio tem a ver com teatro. Trata-se de uma grande, uma descarada mistificação. (Diário de Lisboa, 25-04-1969)

$\mathrm{Na}$ defesa de alguns princípios estéticos, culturais, e civicos, Joaquim Benite tentou sempre matizar a sua avaliação, admitindo que em espectáculos de grande valor poder-se-iam encontrar, apesar de tudo, alguns aspectos menos bem resolvidos. É assim que elogia As mãos de Abraão Zacut, de Sttau Monteiro ("um dos melhores originais portugueses que têm subido à cena nos últimos anos", como escreve no Diário de Lisboa, 19-12-1969), e a encenação de Luzia Maria Martins para o Teatro Estúdio de Lisboa. Mas, percebendo embora o valor literário do texto e a sua recriação teatral, sinalizava pormenores que poderiam ter merecido uma melhor afinação: ser mais depurada a solução cénica, por exemplo, retirando qualquer sinal, mesmo vago, de um campo de concentração, ou omitindo o recurso à voz off.

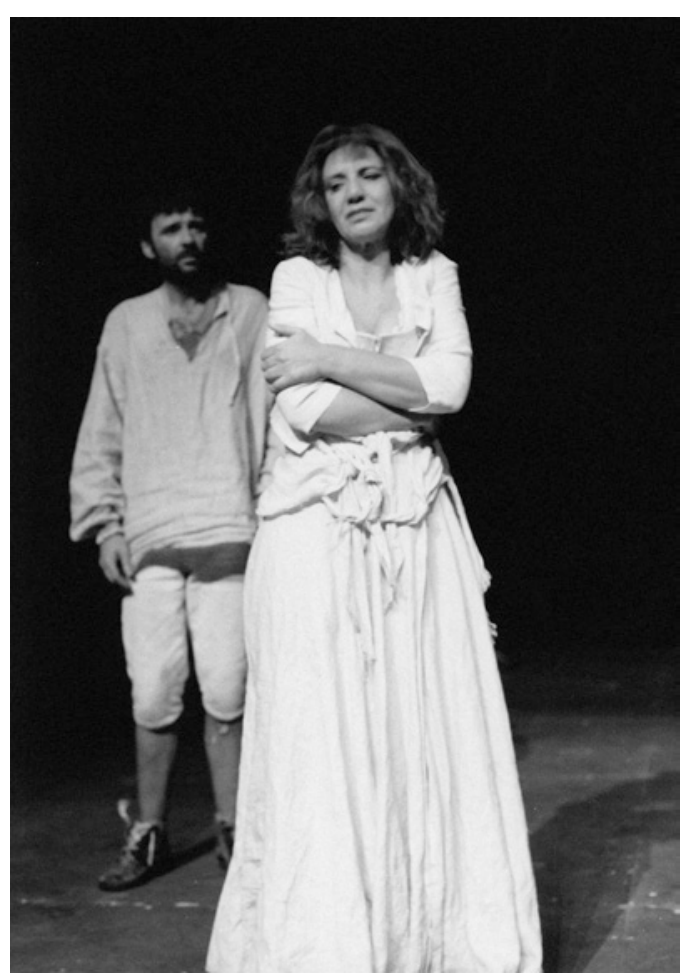

Outro aspecto importante dessa sua vocação crítica está na capacidade de sentir o novo e de o celebrar sem reticências: é o caso, entre outros, da revelação extraordinária do Grupo 4 em Amanhã digo-te por música (Diário de Lisboa, 06-11-1969), do Anfitrião pelo Grupo de Teatro da Faculdade de Letras, com encenação de Luís Miguel Cintra (Diário de Lisboa, 11-05-1969), ou da Oração e Os dois verdugos, pelo TEC, onde reconhece um salto qualitativo de Carlos Avilez que se apressa a publicamente celebrar:

[...] admirável realização que conjuga vários elementos de grande importância [...] Carlos Avilez escolheu o caminho certo da depuração, da renúncia às concepções visualistas que têm predominado nos seus espectáculos. [...] Desta vez não há arbitrio, gratuitidade, mas uma interpretação coerente do texto, traduzida com valores cénicos de estilo unitário e gravemente significantes. (Diário de Lisboa, 23-101969)

2.

Jornalista, portanto, mas crítico de teatro: sabedor, interpelante, justificando a apreciação, não escondendo os aspectos negativos dos espectáculos, mas não recusando o mérito quando o reconhecia.

Mas, como homem de paixões, inteiro na sua articulação entre o pensar e o fazer, rapidamente assumiu essa outra responsabilidade de encenar peças e dirigir uma companhia.

E foi por isso que em 1970 fundou o Grupo de Teatro de Campolide e se iniciou no fazer teatral encenando 0 avançado-centro morreu ao amanhecer, sobre texto do argentino Agustin Cuzzani, que teve público entusiasta e excelente recepção crítica. E encetou por aí um projecto de teatro.

Em virtude de um reportório politicamente comprometido e de um estilo que adoptara "entre a didáctica de Brecht e as formas de revista à portuguesa" o G.T.C. acabou por criar um público fiel e dedicado e soube transformar as 

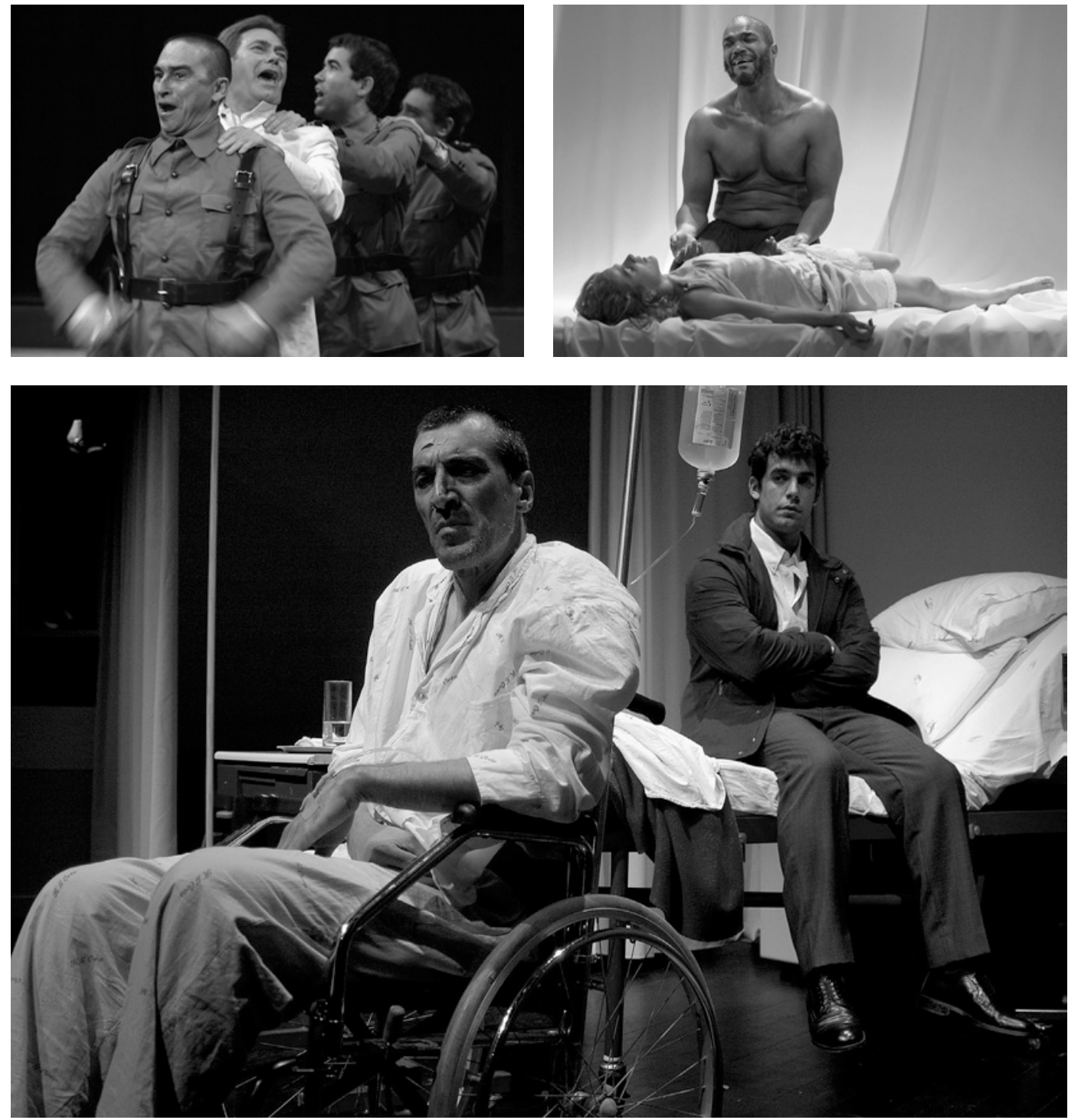

Othello,

de William Shakespeare,

enc. Joaquim Benite,

Companhia de Teatro de Almada e ACTA-A

Companhia de Teatro do

Algarve, 2005

(< Luis Vicente,

Marques d'Arede,

João Evaristo

e Miguel Martins;

$>$ Mário Spencer e Joana

Fartaria),

fot. José Frade.

Quarto minguante,

de Rodrigo Francisco,

enc. Joaquim Benite,

Companhia de Teatro de

Almada, 2007

(Alberto Quaresma

e André Albuquerque),

fot. José Frade.

estreias dos seus espectáculos em "grandes acontecimentos não só culturais como mesmo políticos" (Porto 1985: 50). Como escreve Carlos Porto, analisando o particular estatuto do grupo e a sua actuação, este era um caso singular:

[...] o Grupo de Teatro de Campolide [...] começou por ser constituido por amadores, embora já nessa altura as suas estruturas, a sua organização e os seus objectivos o caracterizassem como grupo profissional. Tendo na equipa um dramaturgo, Virgilio Martinho, que exercia as funções de dramaturgista (figura que só mais tarde surgiria profissionalmente em Portugal), fazendo pesquisas de público através de inquéritos devidamente elaborados e analisados, vindo a formar, já como grupo profissional, a primeira associação portuguesa de espectadores e a editar uma revista especializada Programa. (ibid: 49-50)

0 grupo profissionaliza-se em 1977 e leva à cena no Teatro da Trindade o espectáculo 1383 (uma composição dramatúrgica de Virgílio Martinho sobre a Crónica de D. João / de Fernão Lopes) e Santo inquérito, de Dias Gomes. Ambos foram (e são) visões da nossa História, encenações do humano sob uma perspectiva política lúcida, em versão cénica, cheias de vivacidade, ironia e avaliação crítica de um passado onde podemos encontrar as raízes dos atrasos e bloqueios do presente, mas também o exemplo inspirador da luta para os superar.

No ano seguinte, em 1978, o Grupo instala-se em Almada, passando progressivamente por alguns espaços até chegar, em 2005, ao Teatro Azul, magnífica obra dos arquitectos Manuel Graça Dias e Egas José Vieira.

Sabemos como Almada se destacava já no plano político e cultural por uma declarada militância a todos os niveis: amadora e profissional, associativa e sindical, erudita e popular. Mas Joaquim Benite progressivamente impõe - julgo que o termo é justo - um ritmo, uma exigência e uma dedicação transbordantes: a si próprio, aos seus colaboradores, ao público, aos artistas, à edilidade. Dirige a revista de teatro Cadernos, e a colecção "Textos de Almada", demonstrando que o teatro para ele não se extingue com o final do espectáculo, nem se inicia aí, antes se organiza e ecoa em outras plataformas e va ajudando - pelas letras, pela memória, pelas aprendizagens - a mudar o mundo.

E o Festival Internacional de Teatro de Almada (que se realiza anualmente desde 1984) é a moldura mais visivel dessa energia permanente, fora de horas, sempre documentada de perto por folhetos, jornais, entrevistas, folhas de sala, etc. É, afinal, uma outra dimensão - de 


\section{Tuning, \\ de Rodrigo Francisco, \\ enc. Joaquim Benite, \\ Companhia de Teatro de \\ Almada, 2010 \\ (Pedro Walter \\ e João Farraia),}

fot. Rui Carlos Mateus.

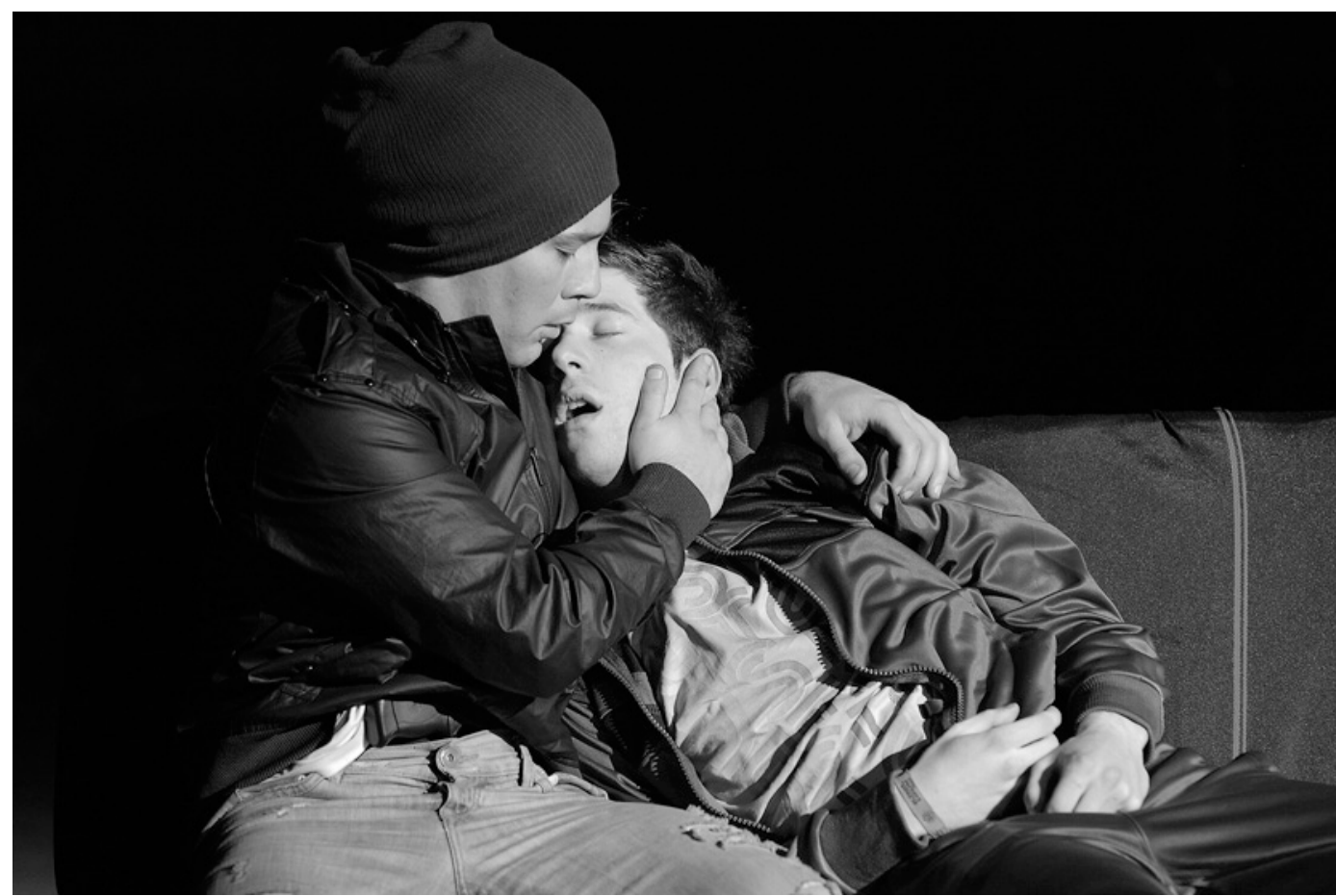

trabalho, de fazer, de organizar, de dirigir - que se abre ao mundo naquelas duas semanas de Julho todos os anos. Com uma vocação internacional, o Festival cria um mundo em que os muitos lugares do mundo se vão cruzando.

Por ele Joaquim Benite tem sabido trazer a Portugal grandes artistas, esplêndidas realizações cénicas, não apenas para deslumbrar o público, mas para todos artistas e espectadores - aprenderem, como explicou recentemente a um jornal:

\footnotetext{
Acho que as pessoas devem ter termos de comparação e não queria obrigá-las a ver apenas o meu teatro. Criei o festival para que o meu próprio teatro fosse confrontado com um maior grau de exigência. Não tenho o complexo provinciano de sermos os melhores da quintinha. Temos de nos confrontar com os melhores. Por vezes somos humilhados, mas aprendemos. Só se cria um público na diversidade (Jornal "I", 01-07-2011, p. 35)
}

E independentemente dos patamares de crescimento e consolidação - nacional e internacional -, o Festival de Almada continua, nas palavras de Joaquim Benite, a sua fidelidade aos seus valores fundamentais: abertura à diversidade, cruzamento de linguagens, confronto de culturas, debate e reflexão, apoio aos jovens.

Como escreveram Sebastiana Fadda e Rui Pina Coelho na revista Sinais de cena:

Corria o mês de Julho de 1984. Portugal ainda não era Europa. Um palco improvisado ao ar livre, no Beco dos Tanoeiros, na zona velha da cidade, fazia Almada fervilhar de vida e excitação: decorria a primeira Festa de Teatro de Almada, uma resenha de teatro profissional e amador de todo o pais, de que ninguém na altura suspeitaria a longevidade e o crescimento.

[...] Aquela que tinha as caracteristicas de uma festa de teatro, improvisada, descontraida e para camadas alargadas de população, começou a ter espaços e datas mais estáveis, eco nacional e internacional, integrando as várias artes de palco, manifestações de teatro de rua e promovendo muitas outras actividades paralelas, radicando também nelas a sua identidade: os concertos, os encontros e as conversas com os criadores e com a crítica, os seminários, as conferências, as exposições e as homenagens. (Sinais de cena, APCT/CET, n. 7 , Junho de 2007, p. 23)

Pelas ruas de Almada (e agora também nas suas várias extensões por Lisboa) expande-se, de facto, uma atmosfera que celebra o teatro em festa. E essa química cultural e artística não pode ser dissociada da figura, do saber e do valor de Joaquim Benite: é - no seu melhor - a sua explícita radiografia pública.

Como homem de cultura, interessa-se pelo teatro em Portugal - o profissional, o amador, o erudito, o descentralizado, enfim, o teatro nas suas múltiplas valências - e valoriza-o pelas suas relações com o mundo. Não se estranha, por isso, que dirija a secção portuguesa do Instituto Internacional de Teatro do Mediterrâneo e seja delegado em Portugal do CELCIT (Centro Latino-Americano de Criação e Investigação Teatral). E que sejam já muitas as referências ao seu trabalho em periódicos internacionais e em estudos mais alongados sobre o teatro em Portugal: pela escrita de Carlos Porto, Luiz Francisco Rebello, Sebastiana Fadda ou José Mascarenhas, entre outros.

Enquanto encenador, cedo percebeu a importância de trabalhar com um dramaturgista, que encontrou em Virgílio Martinho, dedicado companheiro de aventura da sua companhia desde o início: dele fez Filopópulos (1973) 0 grande cidadão (1976), entre outros, e nas suas traduções e trabalho de dramaturgista baseou espectáculos memoráveis como 1383 (1977), sobre texto de Fernão Lopes, As aventuras de Till Eulenspiegel (1978), sobre texto de Charles de Coster, e Fulgor e morte de Joaquim Murieta (1974), sobre texto de Pablo Neruda. Ao autor chileno irá regressar anos mais tarde com a dramaturgia de Carlos Porto que, de forma muito sensivel, reescreveu 0 carteiro de Neruda (1997).

Outros autores portugueses mereceram a sua atenção e permitiram espectáculos inesqueciveis: António José da 


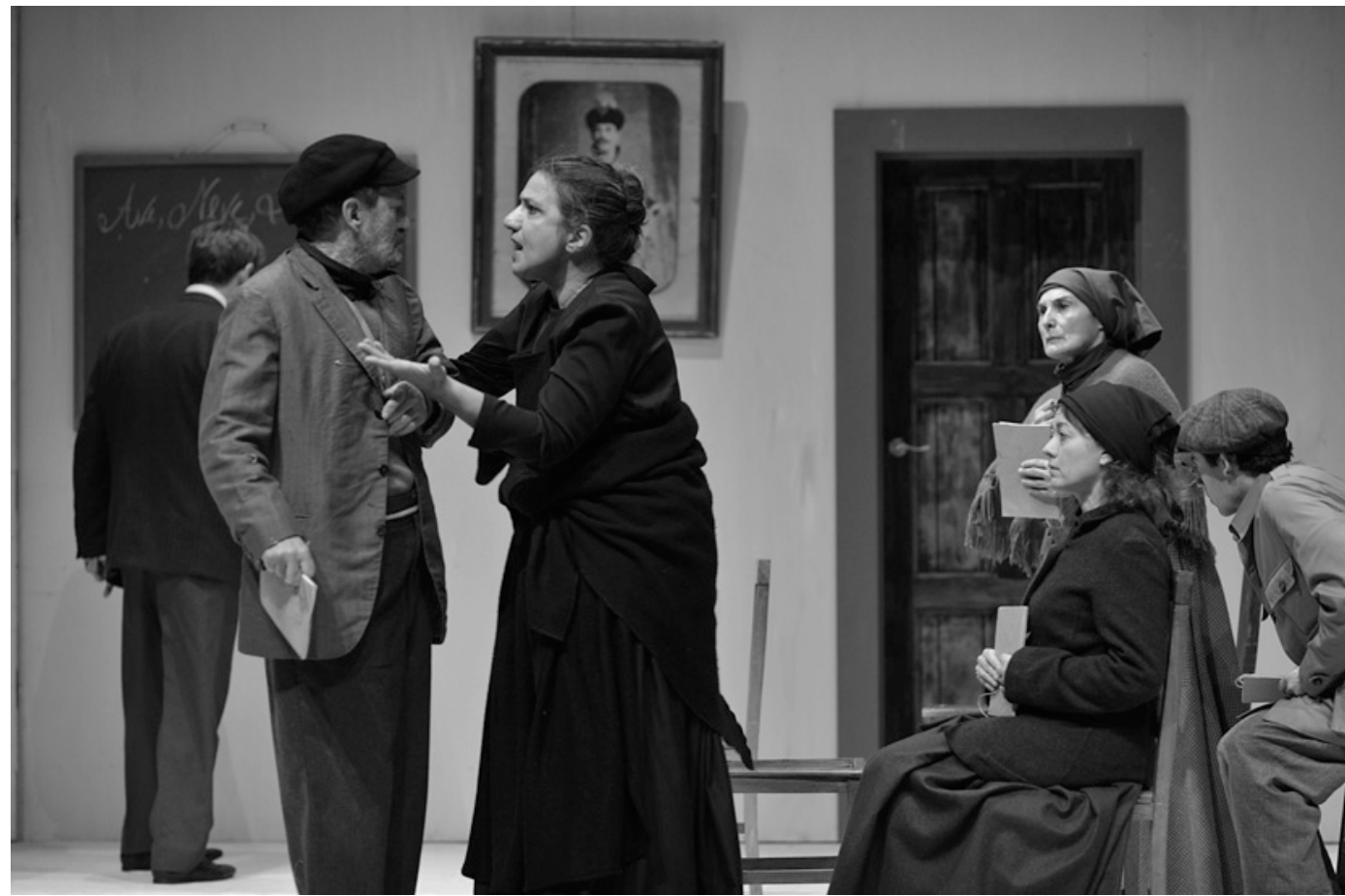

A mãe,

de Bertolt Brecht,

enc. Joaquim Benite,

Companhia de Teatro de

Almada, 2010

(Marques d'Arede

Manuel Mendonça,

Teresa Gafeira,

Teresa Mónica,

Luzia Paramés)

fot. José Frade.

Silva no espectáculo "lendário" A vida do grande D. Quixote de la Mancha e do gordo Sancho Pança (1972), Romeu Correia (Tempos difíceis 1982), Raul Brandão (O doido e a morte, 2009) e sobretudo José Saramago, de quem levou à cena: A noite (1979), Que farei com este livro?(1980), e, com adaptação de Filomena Oliveira e Miguel Real, Memorial do convento (1999).

Entre as suas dramaturgias electivas, no plano internacional, destacam-se Shakespeare e Brecht. E se autores consagrados the vêm merecendo uma atenção continuada, é de destacar também o seu interesse e gosto em autores mais novos que gosta de revelar, sendo importante, neste caso, citar Rodrigo Francisco de quem levou à cena dois textos interessantíssimos pela convocação de um tempo e de uma realidade social que nos toca de muito perto: Quarto minguante (2007) e Tuning (2010).

3.

Reconheço que para marcar repertório, afeiçoar o texto à cena, reunir elenco e convocar o público, é a figura do encenador que sobressai. E por ai Joaquim Benite vem criando a sua partitura muito própria.

Procede a uma análise dramatúrgica em que as questões políticas, culturais e estéticas ganham um sentido historicamente marcado, e conduz o trabalho dos actores de forma sóbria e eficiente. Para o provar, bastaria recordar espectáculos inesqueciveis como 1383(1977), Mãe Coragem e os seus filhos (2000), 0 mercador de Veneza (2002), as suas duas criações cénicas de Othello em 1993 e 2005, e mais recentemente a intensidade emotiva do espectáculo A mãe, de Brecht (2010).

$\mathrm{E}$, ao lado da vontade de compreender e levar à cena os grandes clássicos, vemos o desejo e a intenção de criar um cânone a partir da escrita em português: foi quem primeiro levou José Saramago ao palco com A noite, e quem procurou, em Virgílio Martinho e em autores de gerações diferentes, experimentar o teatro que apresenta e nos fala das realidades que nos são mais próximas.
Mas talvez que o lugar verdadeiramente decisivo no seu caso - aquele em que brilha acima de tudo - é o do grande gestor: dinâmico, voluntarioso, competente, rápido na resposta a dificuldades e problemas, capaz de, com uma insistência obsessiva, vencer no confronto com as instituições.

E, ainda por cima - até pelo seu próprio trajecto - é um gestor atento à imprensa, interessado em cativá-la para a causa teatral, o que vai fazendo com um labor persistente, uma paciência incansável e alguma generosidade.

Homem de cultura, inteligente e sabedor, arrebatado na acção, truculento muitas vezes, Joaquim Benite é, sem dúvida alguma, pelo seu trabalho continuado, pela sua presença tutelar, uma destacada figura da cultura portuguesa que tem visto o seu valor reconhecido também institucionalmente aquém e além fronteiras.

Foi agraciado com a Medalha de Ouro de Mérito Cultural do Ministério da Cultura, a Medalha de Honra do Município da Amadora e a Medalha de Ouro de Mérito Cultural da Câmara Municipal de Almada, e, em 2007, foi distinguido pelo Governo francês com o grau de Cavaleiro da Ordem das Artes e das Letras. Distinções merecidas, um valor reconhecido, sem dúvida.

Com a sua veia satírica bem conhecida, e avesso a deslumbramentos do "social", Joaquim Benite gracejou recentemente: "Agora já me habituei: faço colecção [...] mas não ligo muito a isso. São distinções compensadoras. Sou comendador e cavaleiro em alguns paises, às vezes gozo que nunca mais me mandam o cavalo" (Entrevista ao jornal "I", 01-07-2011).

Embora temporariamente interrompido por um problema de saúde, este é indubitavelmente um notável percurso de vida na cultura, na arte e na política.

\section{Referência bibliográfica}

PORTO, Carlos et. al. (1985), Dez anos de teatro e cinema em Portugal, Lisboa, Caminho. 